NASA-CR-202410

93053

\title{
Application of QFT to the Problem of Failed In-Flight Controllers During Approach and Landing of a B-720 Aircraft
}

\author{
Hwei-Lan Chou \\ Daniel J. Biezad \\ Cal Poly State University \\ San Luis Obispo, CA 93407
}

\begin{abstract}
Previous studies by NASA Dryden have shown the use of throttles for emergency flight control to be extremely difficult, especially for landing. Flight control using only the throttles to achieve safe landing for a large jet transport airplane, the Boeing 720 , is investigated using Quantitative Feedback Theory. Results are compared to an augmented control developed in a previous study. The controller corrected unsatisfactory open-loop characteristics by increasing system band width and damping, but improving the control band width substantially proved very difficult. The pitch controller is robust in conditions of no or moderate turbulence. The roll controller performed well in conditions of no turbulence, but is sensitive to moderate turbulence. Handling qualities of the augmented control for approach and landing were evaluated by piloted simulation flights.
\end{abstract}

\section{Notation}

$\begin{array}{ll}\text { TOFC } & \text { Throttle-Only Flight Control } \\ \text { QFT } & \text { Quantitative Feedback Theory } \\ C_{m u} & \text { Velocity-pitch rate derivative } \\ C_{l \beta} & \text { Sideslip-roll coupling derivative } \\ q & \text { pitch rate (deg/sec) } \\ \gamma & \text { night path angle (deg) } \\ \beta & \text { angle of sideslip (deg) } \\ \varphi & \text { bank angle (deg) } \\ \theta & \text { pitch angle (deg) } \\ z & \text { thrust (lbs) } \\ \omega_{1} & \text { natural frequency } \\ \zeta & \text { damping ratio } \\ \delta T_{c} & \text { stick input(full deflection=l unit) } \\ K_{\mathbf{q}} & \text { pitch rate feedback gain } \\ K_{\gamma} & \text { flight path angle feedback gain } \\ K_{\beta} & \text { sideslip angle feedback gain } \\ K_{0} & \text { bank angle feedback gain } \\ \mathbf{G}_{\text {in }}^{\text {out }} & \text { transfer functions }\end{array}$

(a) short form of $(s+a)$

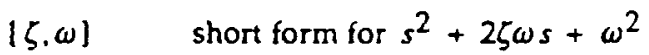

c.g. center of gravity

\section{Introduction}

Through throttle manipulations, engine thrust has been found useful in providing some controllability for multiengine aircraft in emergency situations with severe or complete flight control system failures. This paper focuses on a particular application, a simulation augmented control developed by NASA for Boeing-720 aircraft Throttles-Only Flight Control (TOFC) ${ }^{1-2}$. NASA has found the use of throttles feasiblefor emergency flight control for a range of airplanes, and their analyses for a variety of aircraft are available in the literature ${ }^{3-6}$. This controller was implemented on a high fidelity B720 flight simulator and obtained generally good pilot ratings by increasing the bare airframe Dutch-roll and phugoid damping. The primary aim of this study is to present an alternative control design technique based on Quantitative Feedback Theory(QFT) to further improve the Dutch-roll damping and to increase controller band width for better handling qualities.

The QFT technique ${ }^{7}$ was chosen because of the insights it provides throughout its design process. It allows designers to specify a desired closed-loop frequency response with a desired control band width and damping characteristic. It shows why the desired performance may not be achieved within the given control actuation and rate limits.

In this paper a QFT augmented throttle-only flight path controller for approach and landing is presented. Complete details of the aircraft model and justification for TOFC are not included, but the reader is reminded that "trimming" must be possible and "controllability" must exist. Augmented control design using QFT is presented in a summary fashion. The full justification and step by step procedure may be found in Reference 8 . 
Flightpath

Angle loop

Prefilter

Compensation

Pitch Rate

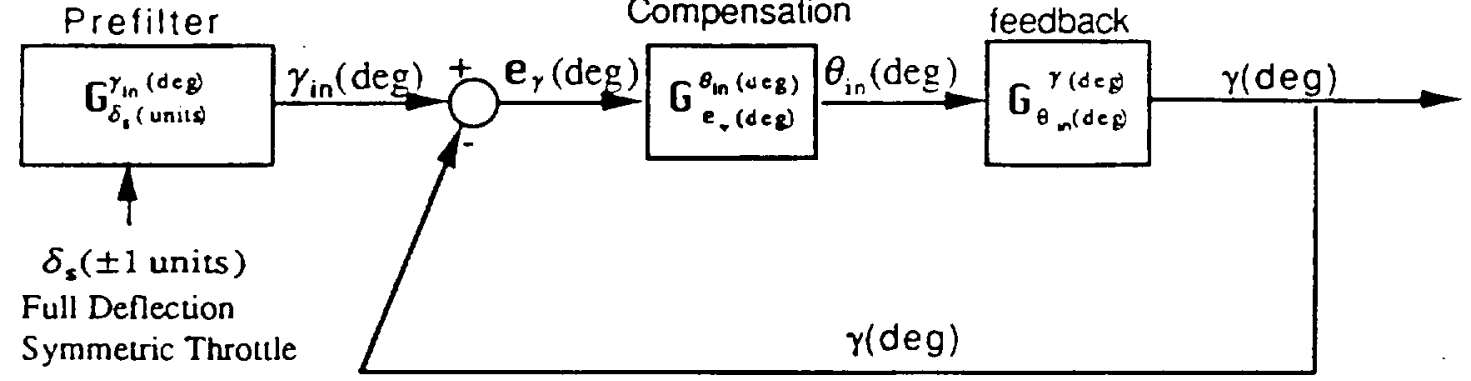

Figure 1. Flight Path Angle Control Block Diagram with Inner Loop Closed

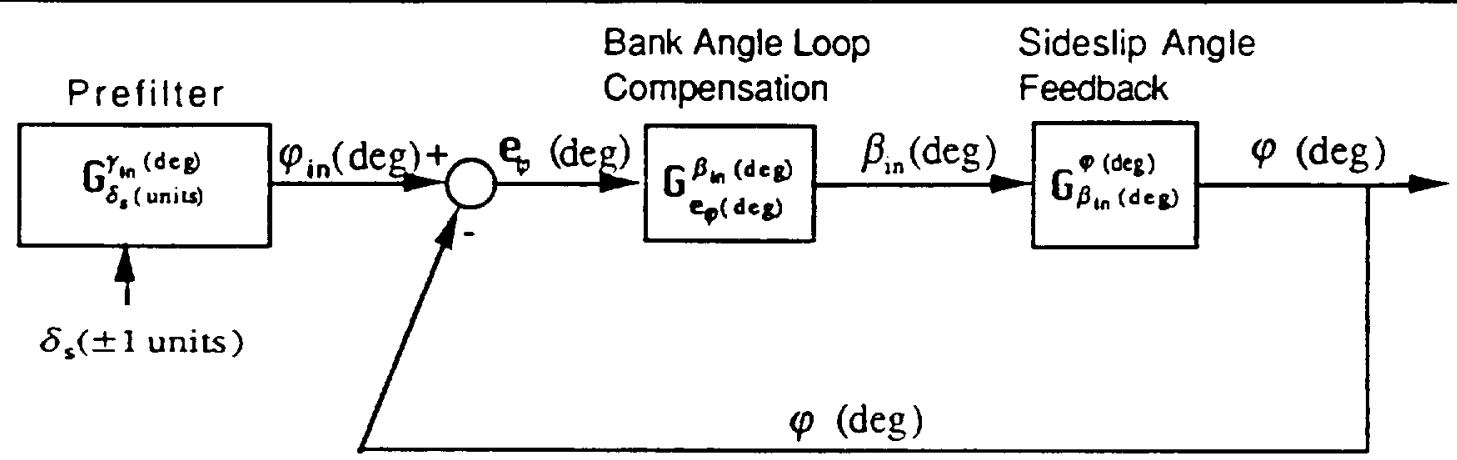

Figure 2. Bank Angle Control Block Diagram with Inner Loop Closed

\section{B-720 Linear Model}

The empirical transfer function developed for the engines is given in short form notation by

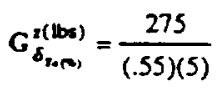

Severe band width attenuation occurs beyond frequencies of $1 \mathrm{rad} / \mathrm{sec}$. For this application his prevented the increase the closed-loop band width beyond $1 \mathrm{rad} / \mathrm{sec}$ within the range of available thrust (see Ref. 6).

Four configuration variations for the $B-720$ were considered as described in the Appendix. They are charactcrized in both the longitudinal and lateral axes by excessive resonance, low phase and gain margins, low crossover frequency, and large phase angle roll-off.

\section{QFT Controller Design}

To apply QFT, the aircraft model is rearranged in a unit feedback form as shown in Figures 1 and 2 . The inner pitch rate and sideslip loops were closed using $\mathrm{Kq}=60$ and $K_{\beta}=4$, which were the settings for the original simulation augmentation scheme.

\section{Rerformance Specification}

QFT allows designers to specify a desired clusedl. .p frequency response with an upper bound $B_{u}$ a lower bound $\mathrm{B}_{\mathrm{L}}$ and a tolerance $\delta_{\mathrm{R}}$ specified to obtain robust performance. The maximum $M_{m}$ is also given to obtain a desired system damping.

Table 1. QFT Performance Specification

\begin{tabular}{|c|c|c|c|c|c|c|c|}
\hline Freq.(r/s) & 0.1 & 0.3 & 0.5 & 0.7 & 1.0 & 2.0 & 5.0 \\
\hline$B u(d B)$ & 17.0 & 17.0 & 17.3 & -16.0 & -4.0 & 20 & -13.0 \\
\hline$B(\mathrm{~dB})$ & 16.8 & -15.0 & 12.3 & 4.6 & -12.4 & 7.1 & -23.0 \\
\hline$\delta_{\mathrm{f}}(\mathrm{dB})$ & 0.2 & 2 & 5 & 8.4 & 8.4 & 9.1 & 15.0 \\
\hline
\end{tabular}

The performance specification show'n in Table 1 are the desired closed-loop responses for both the $\gamma$ - and $\varphi$ loops. These two feedback loops are piloted open-loop systems. Additional specifications are ususallly given for piloted systems, such as a desired control band width of 2 $\mathrm{rad} / \mathrm{sec}$. (see Ref. 9 for transport aircraft landing requirements) and a $\mathrm{k} / \mathrm{s}$ slope near the crossover frequency. These added requirements promote good pilot handling qualities. ${ }^{10}$ 


\section{Design Constraints}

Four configurations were used to study the approach and landing of B-720 throttle-only flight control as summarized in Table 2 and in the Appendix. Configuration 1 was used as the nominal confiuration for control design.

Table 2. Flight Configurations for B-720 (Gear Up)

\begin{tabular}{|c|c|c|c|c|}
\hline Conf & $\begin{array}{c}\text { Weight } \\
\text { (lbs) }\end{array}$ & $\begin{array}{c}\text { Alt } \\
\text { (Ft) } \\
\text { (MSL) }\end{array}$ & $\begin{array}{c}\text { A/S } \\
\text { (Kts) }\end{array}$ & $\begin{array}{c}\text { Flaps } \\
(\%)\end{array}$ \\
\hline 1 & 140,000 & 4,000 & 160 & 0 \\
\hline 2 & 140,000 & 4,000 & 145 & 30 \\
\hline 3 & 160,000 & 4,000 & 175 & 0 \\
\hline 4 & 140,000 & 4,000 & 155 & 30 \\
\hline
\end{tabular}

The performance bounds constraint is a curve on the Nichols Chart that shows the performance tolerance, $\delta_{\mathbf{R}}$, from Table 1 at each specified frequency. Satisfying the tolerance constraint guarantees that the variation of the system response due to plant uncertainties will be no greater than $\delta_{\mathrm{R}}$. There is a performance bound for each frequency.

$\mathrm{U}$ contours are also shown on the Nichols Chart. The $U$ contour is a $M$-circle that has the magnitude of $M_{m}$. with part of the circle stretched for uncertainty at high frequencies. By having the open-loop frequency response not penetrate the U contour, the system's damping will be guaranteed no less than the damping selected for $M_{m}$ as a design constraint.

For inner-loop transfer functions $\mathbf{G}_{\theta_{\text {In }}}^{\gamma}$ and $\mathbf{G}_{\boldsymbol{\beta}_{\text {In }}}^{\bullet}$, the parameter variation given by the four configurations can be expressed minimums and maximums. There are tradeoffs between plant parameter variations and performance. The wider the parameter variation, the more restricted the constraints; consequently, more compensation is required. In this application, due to the engine response limits, the performance specification will have to be relaxed because there is not enough control power to provide all the compensation that is required to meet specifications.

The minimum and maximum values of transfer functions, $\mathbf{G}_{\theta_{\text {In }}^{\gamma}}^{\gamma}$ and $\mathbf{G}_{\boldsymbol{B}_{\text {in }}}^{\bullet}$, form the uncertainty template. The QFT control package 11 allows the designer to input maximum and minimum plant parameter variations, but due to the software's limitation of handling the quantity of uncertainties, some of them were averaged. These variations are listed in Figures 3 and 4.
The $C_{\theta_{1, e}(\mathrm{deg})}^{\gamma(\mathrm{deg})}$ of the numinal contiguration(cunfig. 1) is.

$G_{\theta_{-}(\mathrm{deg})}^{\gamma(\mathrm{deg})}$ config. $]=\frac{.01(.203)[.37 .3 .01]}{(.562)[.624, .111][.441,1.57](5.25)}$

and the min. and $\max . G_{\theta_{\text {ta }}(\text { deg })}^{\gamma(\text { deg })}$ are:

$$
\begin{aligned}
& G_{\theta_{-}(\mathrm{deg})}^{\gamma(\mathrm{deg})} \min .=\frac{.0053(.162)[.35,3.01]}{(.40)[.42,1.48][.66, .01](5.19)} \\
& G_{\theta_{-}(\mathrm{deg})}^{\gamma(\mathrm{deg})} \max .=\frac{.01(.28)[.46,3.43]}{(.58)[.45,1.57][.92, .14](5.24)}
\end{aligned}
$$

Figure 3. Longitudinal Mode Parameter Variation

The $G_{\beta_{-}(\mathrm{deg})}^{(\mathrm{deg})}$ of the nominal configuration(config. 1) is

$G_{B_{\text {sed }}^{*(d e g)}}^{\text {(deg) }}$ nominal $=\frac{.09[.47,3.65]}{(.98)[.81, .15][.26,1.07](5.02)}$

and the min. and max. of $G_{\beta_{\text {.e }}^{\text {(deg }}(\mathrm{dcg})}$ are:

$G_{\beta_{m} \text { (deg) }}^{\text {(deg) }} \min =\frac{.06[.45,3.65]}{(.98)[.60, .15][.24, .93](5.01)}$
$G_{\beta_{.}^{\text {(deg) }}}^{\text {(deg) }} \max .=\frac{.09[.61,4.33]}{(1.03)[1.0,20][.29,1.09](5.02)}$

Figure 4 Lateral Mode Parameter Variation

\section{Controller Design Tectnique}

Poles/zeros/gain compensation will be required tc reshape the open-loop transfer functions from $\mathbf{G}_{\theta_{\text {In }}}^{\gamma}$ and $\mathbf{G}_{\beta_{\text {in }}}^{0}$. On the Nichols Chart, gain raises the transfer function curve, a zero bends the curve to the right, and a polc bends the curve to the left. The compensation-selected forms the controller, $\mathbf{G}_{C}$. $\mathbf{G}_{\theta_{1 n}}^{r}$ and $\mathbf{G}_{B_{t n}}^{\bullet}$ after reshaping, become respectively $L_{e \gamma}^{\gamma}$ and $L_{e q}^{\bullet}$, the open-loop transfer functions of the flight path angle and bank angle feedback loops, where $L_{e \gamma}^{\gamma}=G_{e \gamma}^{\theta_{\text {in }}} * G_{\theta_{\text {In }}}^{\gamma}$ and $L_{e q}^{*}=G_{e \varphi}^{\beta_{\text {In }}} * G_{\beta_{\text {In }}}^{\theta} . L_{e \gamma}^{\gamma}$ and $L_{e}$, should be kept on and above the $B o\left(j \omega_{j}\right)$, for each frequency, $\omega_{i}$, on $L_{e \gamma}^{\gamma}$ and $L_{e q}^{\bullet}$ to assure robust performance. $L_{e \gamma}^{\gamma}$ and $L_{e q}^{0}$ must also not penetrate the $U$ contour in order to obtain the desired damping. In this application the additional constraint existed which required the controller to be physically realizable (zeros not outnumbering poles). 


\section{Longitudinal Flight Path Angle Controller}

Transfer function $\mathbf{G}_{\theta_{i n}}^{\gamma}$ and its performance bounds, Bo(j $\left.\omega_{j}\right)$, and $U$ contour are displayed on a Nichols Chart in Figure 5. Since all the frequency points for $\mathbf{G}_{\theta_{1 n}}^{\gamma}$ are below their corresponding $B o\left(j \omega_{j}\right)$.reshaping is required. Pure gain compensation first raises the curve until it touches the $U$ contour as shown in Figure $6\left(G_{\gamma}^{\theta_{\text {in }}}=16\right)$. Compensation is then added to avoid the $U$ contour while satisfying all the $B o\left(j \omega_{j}\right)$ constraints. Note that no realizable poles/zero compensation could be found to do this. A zero at $.1 \mathrm{rad} / \mathrm{sec}$, for example, pulls the whole $G_{\theta_{\text {In }}}^{\gamma}$ curve to the right of the $U$ contour. But then a pole at any location would make the $\mathbf{G}_{G_{1 n}}^{\gamma}$ curve penetrate the $U$ contour. Since a compensator with only one zero is physically ununrealizable for this application, the compensator, $G_{C}$, for the flight path angle feedback loop. $\mathbf{G}_{\mathbf{e}_{r}}^{\theta_{\text {in }}}$, is a pure gain of 16 . The performance bound, hence the system robustness, was left unsatisfied.

The frequency response of the close-loop transfer function, $\mathbf{T}_{\gamma_{\text {in }}}^{\gamma}$, where $T_{\gamma_{\text {In }}}^{\gamma}=\mathrm{L}_{\mathrm{e} \gamma}^{\gamma} /\left(1+\mathrm{L}_{\mathrm{e} \gamma}^{\gamma}\right)=\left(\mathbf{G}_{\mathrm{e} \gamma}^{\theta_{\text {1n }}} * \mathbf{G}_{\theta_{\text {in }}}^{\gamma}\right) /\left(1+\mathbf{G}_{\mathrm{e} \gamma}^{\theta_{\text {In }}} * \mathbf{G}_{\theta_{\text {in }}}^{\gamma}\right)$ is shown in Figure 7. It can be seen in Figure 7 that $\delta_{\Gamma}$, the spread between $T_{\max }$ and $T_{\min }$, has exceeded the $\delta_{\mathbf{R}}$ over the frequency range .1 to $.7 \mathrm{rad} / \mathrm{sec}$. This is because ${ }_{\mathrm{ey}}^{\gamma}$ did not satisfy the performance bounds over that frequency range. The frequency plot of the close-loop response after adding a prefilter is shown in Figure 8 . A pure gain prefilter of 6 proved most effective in increasing the band width and in meeting the prescribed specification.

\section{Lateral Bank Angle Controller}

Transfer function $\mathbf{G}_{\boldsymbol{B}_{\text {in }}}^{\circ}$ and its perforinance buunds, Bo(j( $\left.\omega_{j}\right)$, and $U$ contour werc similarly analyzed on a Nichols Chart. $\mathbf{G}_{B_{\text {in }}}$ was not only below all the Bo(j$\left.\omega_{j}\right)$ but also penetrated the $U$ contour. A controller, $G_{\mathrm{e}}^{\beta_{1 n}}=(s+.15) /(s+1.5)$, was added to $G_{\beta_{\text {in }}}^{*}$ to reshape it. $L_{e}$ is shown on a Nichols Chart in Figure 9 and t... requency plot of the close-loop transfer function, $T_{\theta_{\text {in }}}$, where

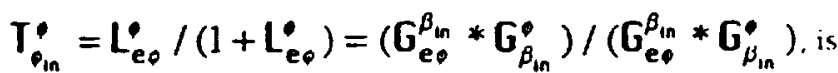
shown in Figure 10 which show's the close-loop frequency response of $T_{\text {in }}^{\bullet}$ after reshaping but with no prefilter applied yet. Sufficient gain is available here. A lead compensator of $(S+1) /(S+2)$ is added to haunch up the severely deteriorated curve at frequencies over $1 \mathrm{rad} / \mathrm{sec}$, and a lag compensator of $(S+.25) /(S+.15)$ is added to steeper the gain curve at low frequencies to provide a smoother $\mathrm{k} / \mathrm{s}$ curve for good pilot handling qualities. The close-loop response after adding the prefilter is similar to Figure 8 , The prefilter selected is $15(S+.25)(S+1) /((S+.15)(S+2))$.

\section{Results and Discussion}

For bank angle control using only the throttles, $\beta$ feedback was found effective in increasing Dutch-roll damping. Bank angle feedback is crucial to lateral phuguid damping. Yaw rate feedback, on the other haud, increases Dutch-roll damping very little and actually decreases the lateral phugoid damping. Tables 4 and 5 compare the dynamic modes of the bare airframe with those from the augmented control implemented in a previous simulation study (References 1 and 2 ), and with those frum the QFT implementation.

Table 3. Longitudinal Mode Comparison

\begin{tabular}{|c|c|c|c|c|c|c|c|c|c|}
\hline & Density & Phugoid & $\begin{array}{l}\text { Short } \\
\text { Period }\end{array}$ & Engine & $\begin{array}{l}\text { Pre- } \\
\text { Filter }\end{array}$ & $G_{e_{n}}^{\theta_{n}}$ & $C_{t_{0}}^{\delta_{T_{c}}}$ & $K_{y}$ & $K_{q}$ \\
\hline $\begin{array}{c}\text { Bare } \\
\text { Airframe }\end{array}$ & $(1.4 \mathrm{E}-6)$ & $(.04 . .13)$ & $(.65,1.4)$ & $(.55)(5.2)$ & * & * & 4 & * & * \\
\hline $\begin{array}{l}\text { Simulation } \\
\text { Augmented } \\
\text { Control }\end{array}$ & $(4.7 E-6)$ & $(.52, .24)$ & $(.52,1.5)$ & $(.4)(5.2)$ & 10 & 1 & 10 & 1 & 4 \\
\hline $\begin{array}{c}\text { QFT } \\
\text { Augmented } \\
\text { Control }\end{array}$ & $(3.4 E-6)$ & $(.62, .32)$ & $(.46,1.6)$ & $(.3)(5.2)$ & 6 & 16 & 1 & 1 & 60 \\
\hline
\end{tabular}




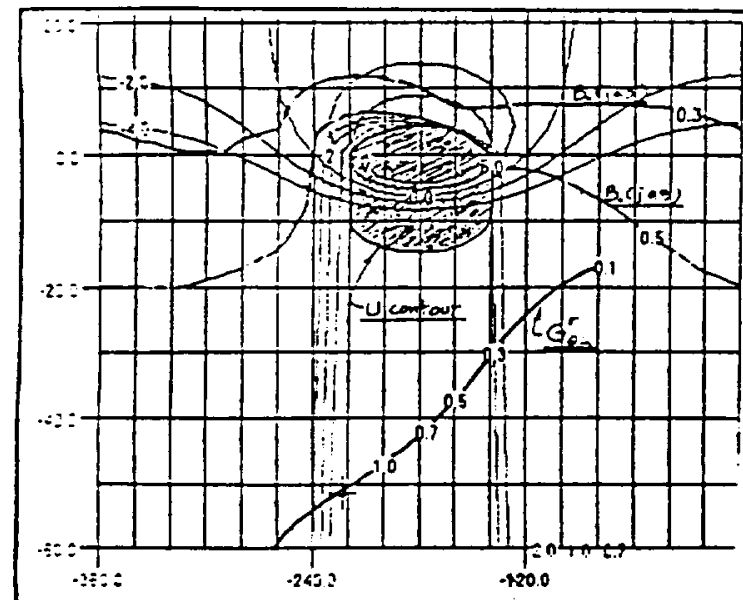

Figure 5. Transfer function $\mathbf{G}_{\theta_{\text {in }}}^{\gamma}$, its performance bounds $B(j w)$, and $U$ contour on Nichols Chart

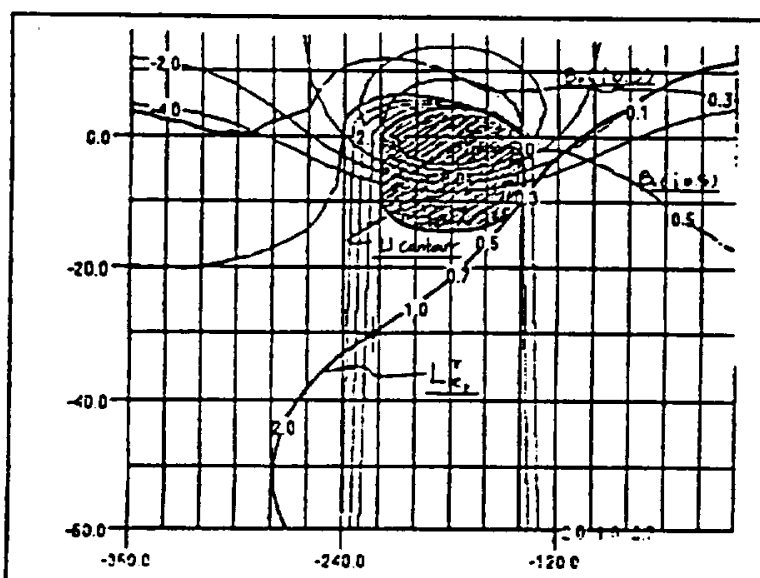

Figure 6. Open-loop transfer function, $\mathrm{L}_{\theta_{\mathrm{in}}}^{\gamma}$

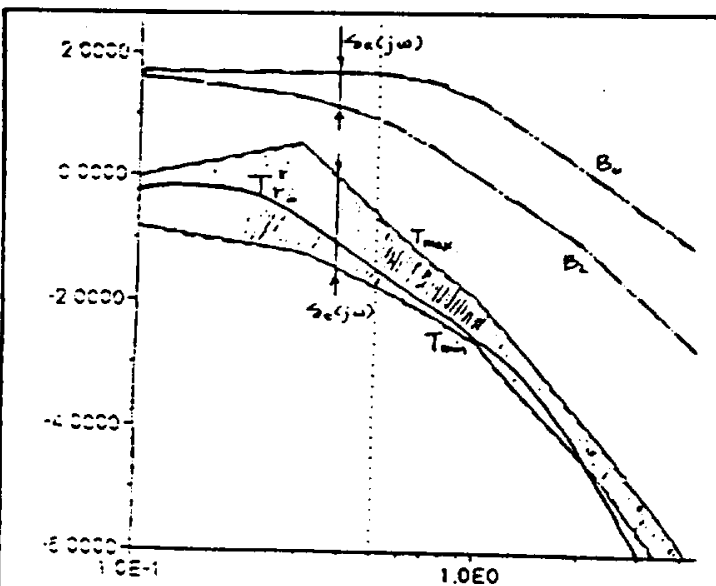

Figure 7. Frequency plot of the close-loop transfer function $T_{\gamma_{\text {tn }}}^{\gamma}$ with no prefilter
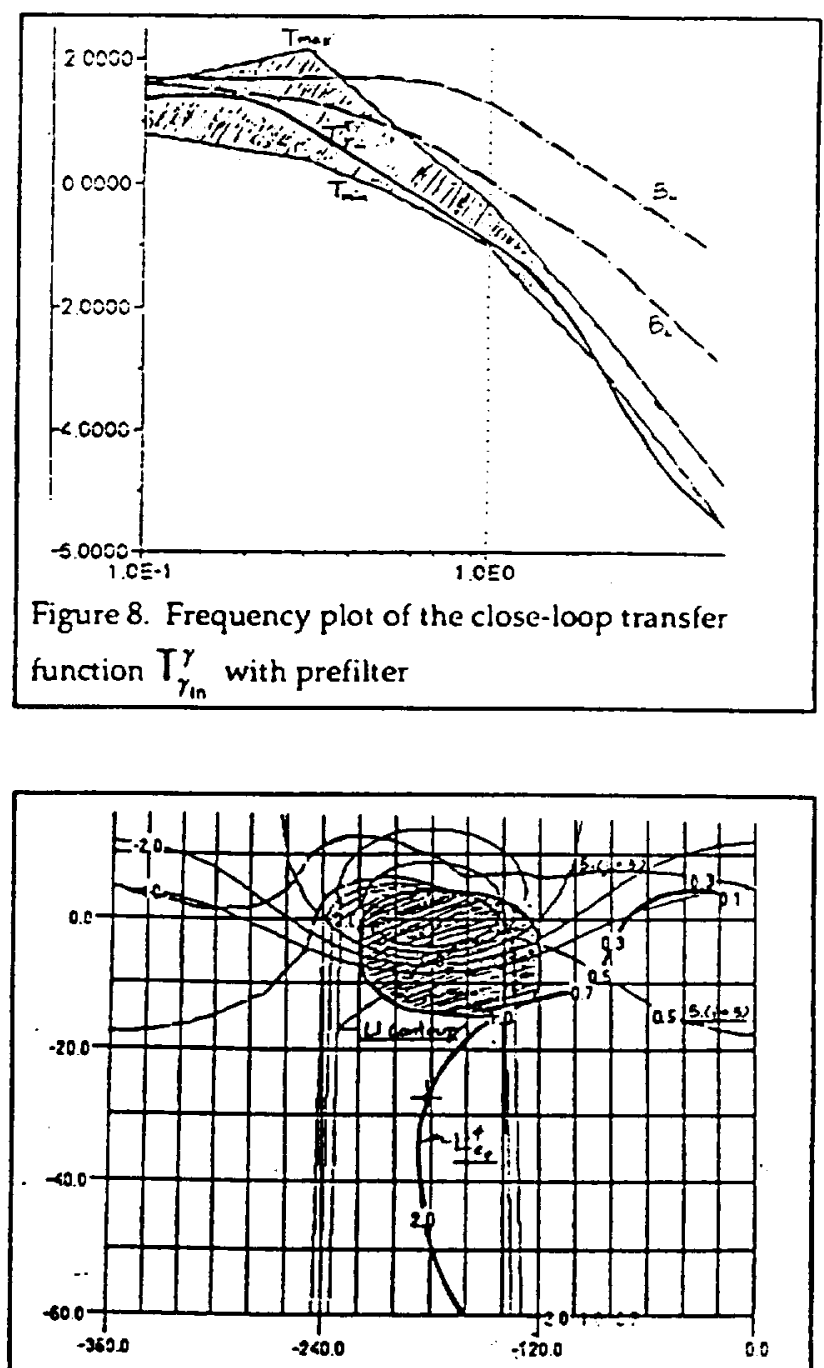

Figure 9. Open-loop transfer function, $L_{e_{p}}$, on Nichols Chart

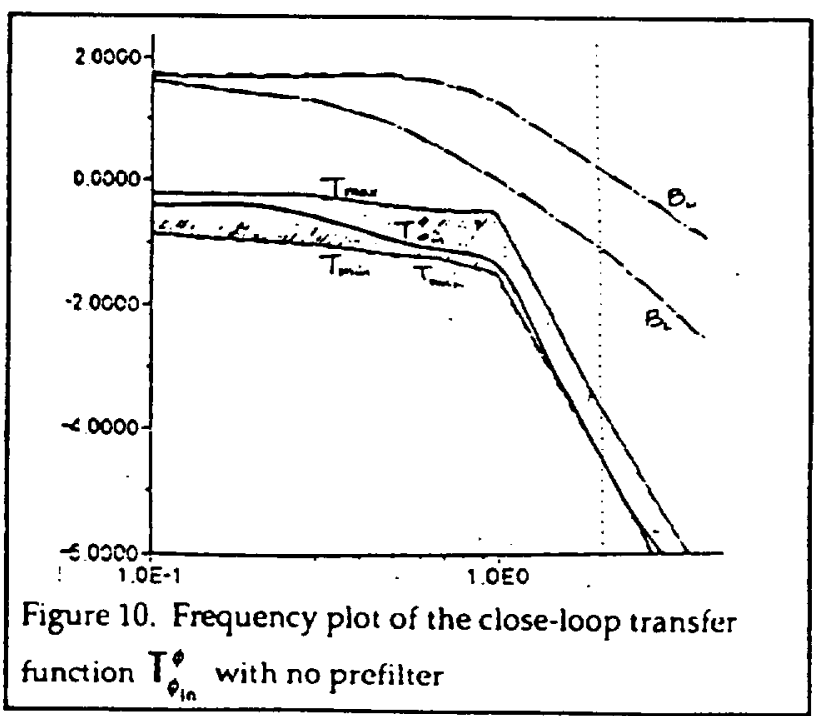


Table 4 Lateral Mode Comparison

\begin{tabular}{|c|c|c|c|c|c|c|c|c|c|c|}
\hline & Spiral & $\begin{array}{l}\text { Dutch } \\
\text { Roll }\end{array}$ & Roll & Engine & $\begin{array}{l}\text { Pre- } \\
\text { Filter }\end{array}$ & $G_{e}^{\beta}$ & $G$ & $K_{0}$ & $K_{\beta}$ & $K_{p}$ \\
\hline $\begin{array}{c}\text { Bare } \\
\text { Airframe }\end{array}$ & $(1.1 E-4)$ & $(.12, .99)$ & (1) & $(.55)(5)$ & $*$ & $*$ & $*$ & * & $*$ & $*$ \\
\hline $\begin{array}{c}\text { Simulation } \\
\text { Augmented } \\
\text { Control }\end{array}$ & $(.73, .35)$ & $(.15, .99)$ & (1) & (5) & 40 & 1 & 1 & .5 & 1 & 5 \\
\hline $\begin{array}{c}\text { QFT } \\
\text { Augmented } \\
\text { Control }\end{array}$ & $(.39)$ & $(.29,1.0)$ & (15) & $(.45)(5)$ & $\frac{2.5(.25)}{(1.25)}$ & 1 & 1 & $\frac{(.15)}{(1.5)}$ & 4 & $*$ \\
\hline
\end{tabular}

For longitudinal control, pure gain compensation was used. The short period mode has a frequency near 1.5 $\mathrm{rad} / \mathrm{sec}$, which is beyond the frequency that the throttles can control. Therefore, the primary concern was to increase phugoid damping and frequency. The short period damping decreased from .52 to $.46 \mathrm{rad} / \mathrm{sec}$. while the phugoid damping and frequency increased from .52 to .62 and from $.24 \mathrm{rad} / \mathrm{sec}$ to $.32 \mathrm{rad} / \mathrm{sec}$, respectively. This increase of response frequency can also be easily seen on the night path angle response (not shown here).

For lateral control where pole/zero compensation was used, the Dutch-roll damping was almost doubled, from 15 to .29 . The "simulation augmented controller" caused a lateral phugoid mode. $1.73, .35]$, which combines the spiral and the slow engine mode. The QFT controller climinated the lateral phugoid mode and resulted in higher damping for the Dutch roll mode (0.29 versus 0.15 ).

\section{Turbulence Response}

The response of the QFT flight path controller under intermediate turbulence was excellent. Since gusts were input, more than one simulation run was made to examine the tracking integrity under turbulence. Both controllers performed well, but the lateral QFT controller showed undue sensitivity to $K_{\beta}$ during bank angle tracking.

During investigation of the bank angle tracking problem, it was found that the $\beta$ being feedback in the simulation was the $\beta$ at the c.g. instead of at the nose boom. The nose boom $\beta$ was then modeled into the $B-720$ simulator, which improved the bank angle tracking under turbulence. The $\beta$ at the nose boom has two extra terms, one a function of roll rate, the other a function of yaw rate. It was thought that the extra yaw rate term might have stabilized the bank angle tracking (the roll rate term was to small and was reglected.)

System response to configuration variations, for flight path control and for bank angle control, was very good. The robustness of the flight path control was improved by QFT. The Dutch-roll oscillation in the original simulation compensation was taken out by QFT compensation; however, the tracking did not improve.

\section{Conclusions and Recommendations}

For throttles-only pitch control using a QFT controller, the control bandwidth, tracking and control robustness were improved by QFT. For bank angle control, QFT has improved the Dutch-roll oscillation problem and performed well under no turbulence. However, the lateral phugoid tracking under intermediate turbulence did not perform well. Apparently a compromise is required between Dutch-roll and lateral phugoid mode damping. Further investigation is recommended for bank angle tracking under turbulence. The impact of system nonlinearities, such as rate and thrust limits, was significant and resulted in a decrease in the bandwidth specification used in the QFT analysis.

\section{Acknowledgment}

This work was made possible by NASA Grant NCC 2-711. Thanks also goes to Mr. Glen Gilyard , Mr. Bill Burcham , and Jeanette Le at NASA Dryden for their technical support and guidance. 
1. Burcham, F., Fullerton G., Gilyard, G., Conley.J. and J. Stewart, "A Preliminary Investigation of the Use of Throttles for Emergency Fight Control," NASA T.M. 4320, 1991.

2. Gilyard, G.B., Conley, J.L., Le, J., and F.W. Burcham, "A Simulation Evaluation of a Four-Engine Jet Transport Using Engine Thrust Modulation for Flight Path Control," AIA A-91-2223, 27th Joint Propulsion Conference, June 24-26, 1991, Sacramento, CA.

3. Azzano, C.P. "A Preliminary Look at Optimal Multi-Variable Design of Propulsion-Only Flight Controllers for Jet Transport Aircraft," NASA Dryden TR, Sept 21, 1990.

4. Biezad, D.J., The Propulsive-Only Flight Control Problem," NAECON, Vol 2, pp494-500, Dayton, Ohio, May 20-24, 1991.

5. Biezad, D.J. and C.P. Azzano, "Designing Low Band width Propulsive-Only Flight Controllers", AlAA Guidance, Navigation, and Control Conference, Paper \#912628CP, pp 267-275, August 12-14, 1991, New Orleans, La.

6. Chou, Hwei-Lan and D.J. Biezad, "Pilot-in-theLoop Analysis of Propulsive-Only Flight Control Systems," Natiofal Aerospace Electronics Conference, Vol. 2, pP 482488, Dayton, Ohio, May 1822, 1992.

7. Horowitz,I. M. and Sidi,M., "Synthesis of feedback systems with large plant ignorance for prescribed time-domain tolerances" Int. I. Control, Vol.16, pp.287-309, 1972.

8. Chou, H.L., "Low Band width Robust Controllers for Flight," Master's Thesis, Cal Poly State University, 1993.

9. Sarrafian, S.K., and Powers, B.G., "Application of Frequency Domain Handling Qualiities Criteria to the Longitudinal Landing Task." NASA Technical Memorandum, Aug. 1985.

10 MIL-STD-1797A, "Flying Qualities of Piloted Vchicles", limited distribution, ASD/ENES, WrightPatterson AFB, Ohio, 30 Jan 1990.

11. Yaniv, O., “Multiple-input single-output (MISO) User Manual, Tel-A viv University, 1991.
Longitudinal Transfer Functions:

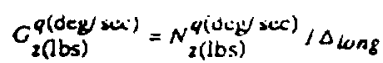

$$
\begin{aligned}
& G_{z(\mathrm{lbs})}^{\gamma(\mathrm{dcg})}=N_{z(\mathrm{lbs})}^{\gamma(\mathrm{dcg})} / \Delta_{\text {long }}
\end{aligned}
$$

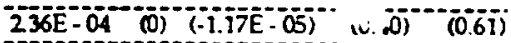

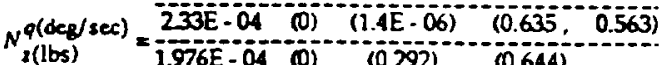

$$
\begin{aligned}
& 1.955 E=04-0)(068-06)(0.819-0.508)
\end{aligned}
$$

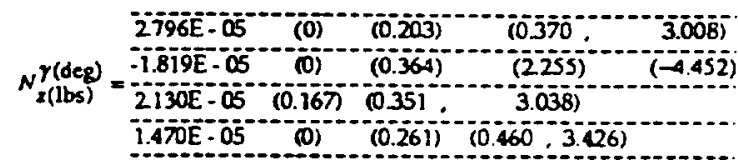

\begin{tabular}{|c|c|c|c|c|}
\hline$(1.438 E-05)$ & $0.918 \mathrm{E}-02$ & 0.1301 & $(0.652$ & 1.382 \\
\hline$(1.101 \mathrm{E}-05)$ & $(8.023 \mathrm{E} \cdot 02$ & 0.147 & 10.596 & 137 \\
\hline $\begin{array}{l}(3.949 \mathrm{E} \cdot 02 \\
(1.878 \mathrm{E}=05)\end{array}$ & $0.190 \mathrm{E}-02$ & $\begin{array}{l}(0.649 \\
0.138)\end{array}$ & $\begin{array}{l}1.3011 \\
0.588\end{array}$ & \\
\hline
\end{tabular}

Lateral Transfer Functions:

$$
\begin{aligned}
& G_{z(\mathrm{lbs})}^{\beta(\mathrm{deg})}=N_{3(\mathrm{lbs})}^{\beta\left(\mathrm{ded}^{\prime}\right)} / \Delta_{\mathrm{lat}}
\end{aligned}
$$

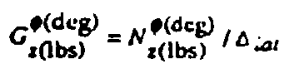

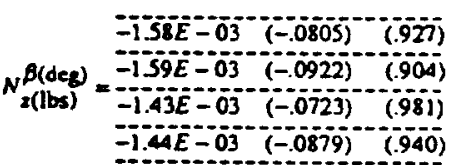

$$
\begin{aligned}
& N_{\text {u(bs) }}^{\text {(deg) }}=\frac{215 E-04-(619-417)}{2.89 E-04} \\
& (.0001)(1.01)(.116,1.05) \\
& -(.006)-(1.05)(0.067,0.93) \\
& \Delta_{\text {bat }}=-(.0028)(1.06)(114,1.08) \\
& (0065)(1.09)(060, .944)
\end{aligned}
$$

